\section{AN IMPROVED TONSIL SNARE}

WILLIAM D. BLACK, M.D.

Ear, Nose and Throat Surgeon at Centenary, Osborne and City Hospitals

ST. LOUIS

The instrument and its various parts are so well shown in the illustrations that no further description is necessary. It is a more powerful instrument than the ordinary tonsil snare and does not get out of order like many others. It is simple in application, can be used a number of times without requiring a new wire, and, if
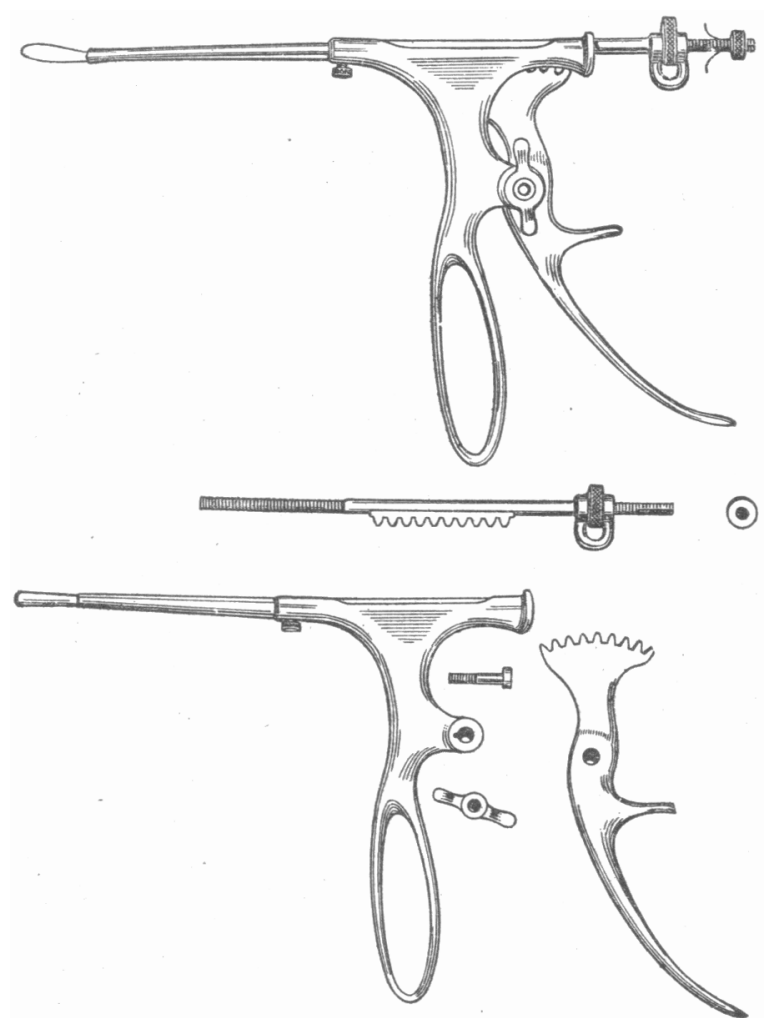

W. Black's tonsil snare and its various parts.

properly adjusted, the wire cannot slip. It should be manipulated by a sort of forearm and wrist movement, insteal of by the fingers, in closing it, so that the barrel will not be thrown out of line. It is made of solid brass with a heavy nickel coating. Number 7 or 8 piano wire shonld be used. I have used the instrument a number of times with excellent results. It is made by the O'Brien Worthen Co., Frisco Building, St. Louis.

220 Metropolitan Building.

\section{A SIMPLE DROP METHOD OF GIVING RECTAL ENEMAS OF NORMAL SALINE SOLUTION}

JOHN EGERTON CANNADAY, M.D.

Surgeon to the Charleston renelal and McMillan Hospitals CHARLESTON, W. VA.

Nurses in hospitals often experience a good deal of trouble in giving patients normal salt solution by rectum. For various reasons it becomes intolerable to the bowel and is expelled. Sometimes the solution is too hot, sometimes too cold, but the most frequent trouble is that it is allowed to run into the rectum too rapidly. The reasons for this are as a rule, first, that the nuirse has no efficient means of making it flow drop by drop, and secondly, that the douche bag or container is usually hung too high and the water pressure is too great. The container should be hung so that the solution is 8 or 10 inches above the level of the rectum. It should frequently be tested by a bath thermometer and the temperature kept about $100 \mathrm{~F}$. A hot-water bottle on either side of the douche bag or the frequent addition of small quantities of hot saline solution will serve to keep the temperature up.

I have found that the most simple means of inducing the fluid to flow drop by drop is not a hemostat but a hairpin and a match. When the hemostat is clamped on the tube it invariably begins to cut into the rubber and probably five minutes after the solution has been flowing drop by drop it is running in a steady stream. A much better, simpler method, and one which will issue a steady drop by drop How as long as is desired, is provided for as follows: An ordinary wire hairpin is passed about the rubber tubing so that one of its prongs extends on either side; the free ends are secured from spreading apart by a twist of the wire with the fingers. Three or four wooden toothpicks or a match trimmed down to a wedge-shaped point are induced between the wire hairpin and the rubber tube and gently pushed in until the flow is just as desired. As a rule it is not wise to at-

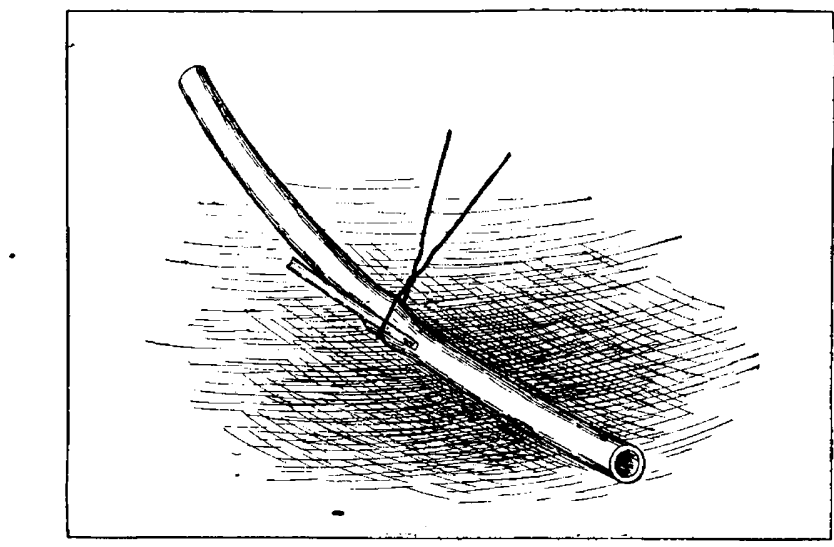

Method of regulating flow in rectal enema.

tempt to give too much fluid at a time. I find that in the average case about 6 or 10 ounces every hour and a half or two hours will be sufficient and will be a little less than the patient will tolerate comfortably. In giving saline solution regularly over a space of more than twenty-four hours one will find that more is usually absorbed at first than later after the system has been saturated with fluid.

A soft rubber catheter in the rectum is better borne and causes much less irritation, as a rule, than a rigid nozzle. If this catheter is made after the type of the usual retention catleter or if it is secured in place by a strip of adhecive plaster passed across the buttocks the patient is saved from the annoyance of frequent introduction and removal.

Aside from the well-known value of saline solution by rectum in the treatment of shock, thirst and hemorrhage, it is perhaps of greater value still in the prevention of urinary irritation and suppression. Usually the operative patient is depleted of water by purgation and gets but little fluid for several hours prior to, during, and after operation. A considerable amount of toxic and highly irritant material is thrown undiluted on the kidneys and they may prove unequal to the strain. If these toxic bodies are highly diluted with water their elimination will be felt far less. 